\title{
Prevalence and Antibiotic Resistance Patterns of Gram-Negative Uropathogens among Paediatric Patients in Nigeria
}

\author{
Esther Claire Alechenu' ${ }^{1}$ Justus Amuche Nweze ${ }^{*}{ }^{\circledR}$, Nathaniel Isaiah Lerum1, \\ Emmanuel Aniebonam Eze ${ }^{1}$ \\ ${ }^{1}$ Department of Microbiology, Faculty of Biological Sciences, University of Nigeria, Nsukka, Nigeria \\ ${ }^{2}$ Department of Science Laboratory Technology, Faculty of Physical Sciences, University of Nigeria, Nsukka, Nigeria \\ Email: *justus.nweze@unn.edu.ng
}

How to cite this paper: Alechenu, E.C., Nweze, J.A., Lerum, N.I. and Eze, E.A. (2019) Prevalence and Antibiotic Resistance Patterns of Gram-Negative Uropathogens among Paediatric Patients in Nigeria. Open Journal of Medical Microbiology, 9, 215-229.

https://doi.org/10.4236/ojmm.2019.94020

Received: September 10, 2019

Accepted: December 15, 2019

Published: December 18, 2019

Copyright $\odot 2019$ by author(s) and Scientific Research Publishing Inc. This work is licensed under the Creative Commons Attribution International License (CC BY 4.0).

http://creativecommons.org/licenses/by/4.0/

c) (i) Open Access

\begin{abstract}
Objective: This study aimed to detect and compare the frequency and antibiotics resistant pattern of Gram-negative uropathogens implicated in urinary tract infections (UTIs) in paediatric patients attending some hospitals in Nigeria and to proffer recommendations for its management. Methods: Based on standard procedures, midstream urine samples were collected. Urinalysis was done as a preliminary diagnosis of UTI using Combi-9 test strip. Isolation of uropathogen was done and antibiotic sensitivity test was carried out using Kirby-Bauer technique. Results: Out of 489 samples collected, 130 (26.4\%) was positive for UTI. The prevalence rate of UTI in the investigated areas such as Nsukka, Otukpo, Gboko and Kastina Ala was 31.8\%, 17.5\%, $34.3 \%$ and $17.1 \%$, respectively. The prevalence of UTI was higher in males 81 (30.9\%) than in females 49 (21.6\%), but there was no statistically significant association between gender and UTI $(p=0.636)$. The prevalence of UTI was greater among the age of $2-5$ years $(28.2 \%)$ and decreased with the increase in age, although there was no significant association between UTI and the age groups $(p=0.870)$. Generally, Klebsiella pneumonae $(88.8 \%)$ was the most dominant bacterium (it was even more in males), followed by E. coli (40.6\%), which was more in females, then Pseudomonas spp. (45.0\%) and Proteus mirabilis $(13.8 \%)$. The in-vitro antibiotic susceptibility testing shows that the isolate was highly resistant to Augmentin, Cotrimoxazoel, Amoxicilin and Tetracycline, while some of the isolate shows intermediate resistant to Nitrofurantoin and Nalixidic acid. Ofloxacine and Gentamicin were the most effective antibiotics against the isolates from all the study areas. The isolates
\end{abstract}


had a varied range of MICs and MBCs. Conclusion: $K$. pneumonia predominated all isolates. The resistant patterns of the isolates to some of the antibiotics show that the first line of antibiotics for treatment of UTI in children in these areas is Ofloxacine and Gentamicin.

\section{Keywords}

Urinary Tract Infection, Bacteria, Gram Negatives, Enterobacteriaciae, Antibiotics Resistance/Susceptibility

\section{Introduction}

Urinary tract infection (UTI) is regarded as one of the most serious infections caused by bacteria especially in children population. For some years now, the significance of UTI in children has been progressively acknowledged and diagnosed [1]. Additionally, when antimicrobial therapy is given to a child having UTI appropriately and promptly, a rapid recovery would be achieved and some acute and/or persistent consequences, which include renal scarring, renal function, as well as hypertension, should be averted [2].

Apart from Staphylococcus aureus and Enterococcus, infections of bacteria are also caused by members of the Enterobacteriaciae which include Escherichia coli, Proteus mirabilis, Klebsiella spp. and Pseudomonas aeruginosa [3] [4] [5]. Presently, it is worrisome of the pattern with which these bacterial pathogens resist commonly used antibiotics or antimicrobial agents [1].

Diagnosis of UTI relies on both urinalysis and urine culture; the diagnosis of UTI in children is normally complicated and may be missed. This is because the clinical presentation of UTI may be insignificant and sometimes with nonspecific clinical signs which may include abdominal pain as well as fever that may as well be seen in various acute self-limiting viral illnesses during childhood [2] [6] [7]. For the UTI diagnosis to be confirmed in a laboratory prior to treatment, urine culture as well as testing for antibiotics sensitivity is usually done. But it challenges to collect uncontaminated urine samples from children and infants, who are not toilet trained [2] [8]. In treatment of UTI in children, there are no well-established antibiotics of choice since the sensitivity of the pathogens differs in several locations [9] [10].

In Nigeria, an extensive investigation has not been done the resistance pattern of uropathogens, especially in children, although, there are some studies in some location/healthcare centres in few states [7] [11] [12]. It is in this view that this study was designed to extend the frontiers of available medical information in the areas of UTIs. It is aimed at investigating the prevalence of these Gram-negative bacteria responsible for UTI among children in the areas under study and exploring sensitivity patterns of identified microorganisms to certain antibiotics used in the treatment of UTI. 


\section{Materials and Methods}

The study is a hospital based cross-sectional study conducted between December and April. Ethical approval was obtained from the Chief Medical Director and Ethical Committee of these hospitals: Chidubem Children Specialist Hospital Nsukka, Bishop Shanahan Hospital, and Ochil Hospital, Nsukka, Enugu State; General hospital in Katsina Ala, General hospital in Alaide, St. Vincent hospital, and Comprehensive Health Centre in Benue State. The concept form was given to each patient before samples were collected. Inclusion criteria: patients who are within the age range of 2 - 12 years only. Exclusion criteria: children below one year, above 12 years, and patients who have been on antibiotics for at least three days before the day of sample collection. Midstream urine samples were collected randomly from in and outpatients using sterile universal bottles. Samples were delivered to the laboratory within an hour.

\subsection{Isolation and Identification of Urine Samples}

About $0.001 \mathrm{ml}$ of samples where inoculated into Nutrient agar (Oxoid, United Kingdom) and MacConkey agar (Oxoid, United Kingdom) using micropipette. The media were prepared according to the manufacturer's instructions. After inoculating sample on culture plates, urine microscopy was also done. At $2000 \mathrm{~g}$ for $5 \mathrm{~min}$, each urine samples $(5-10 \mathrm{ml}$ ) were centrifuged (using Teco diagnostic centrifuge), followed by microscopic examination ( $\times 40$ objective) of the wet preparation of the sediment. The presence of pyuria (more than 5 white blood cells per high power field (HPF)) or any bacteria per HPF was noted as significant and suggestive of UTI [2]. Under aerobic condition at $37^{\circ} \mathrm{C}$ for 24 hours, the plates were incubated and colony forming units (CFU) was determined and those that had $\geq 10^{5} \mathrm{CFU} / \mathrm{mL}$ were considered to be significant indication of UTI and were marked for further investigation. The isolates were confirmed with Chromogenic media (Uriselect ${ }^{\text {tm }} 4$ Agar Bio-Rad Laboratory).

Using sterile wire loop, colonies were streaked on prepared molten CHROM agar plates and were incubated aerobically for 24 hours for colour change. Identification of each organism was done following the manufacturer's colour guide; further identification was carried out using biochemical tests following standard techniques [13].

\subsection{Antibiotic Susceptibility Test}

The antibiotics susceptibility test was performed using the Kirby Bauer disk diffusion technique [14] with commercially available disks (ABTEK laboratories). A $0.1 \mathrm{~mL}$ of $0.5 \mathrm{MacFarland}$ standardized isolates (approximately $10^{7} \mathrm{CFU} / \mathrm{mL}$ ) was used and the plates were incubated at $37^{\circ} \mathrm{C}$ for $16-18 \mathrm{~h}$. And according to Clinical Laboratory Scientific Institute (CLSI) approved standard guidelines, the inhibition zones diameter of the antibiotics were measured, recorded and interpreted. The antibiotics tested against Gram-negative bacterial isolate were Augmentine Ofloxacine Gentamicin, Nalixidic Acid, Nitrofurantoin, Cotrimoxazole, Amoxicilin and Tetracycline. 


\subsection{Minimum Inhibitory Concentration (MIC)}

Following the initial antimicrobial screening tests, the minimum inhibitory concentrations of each antibiotic were determined by using broth tube microdilution method as described by Andrew [15], in accordance with CLSI approved standard for bacteria. The antibiotics were dissolved in their different appropriate diluent. Ofloxaxine $500 \mathrm{mg}$ was dissolved in $500 \mathrm{mls}$ of sterile distil water, gentamycin was dissolved in distil sterile water, while nitrofurantoin $100 \mathrm{mg}$ was dissolved in $100 \mathrm{~mL}$ of Dimethylsulphuramide (DMF). $744 \mu \mathrm{l}$ of sterile Mueller Hinton broth was added to $256 \mu \mathrm{l}$ of antibiotics i.e. ofloxacine, gentamycin and nitrofurantoin given a total of $1000 \mu \mathrm{l}$. another $1000 \mu \mathrm{l}$ of sterile Mueller Hinton broth is added to the tube containing the antibiotics and the broth to reduce the concentration to 128 , then $1000 \mu \mathrm{l}$ of is pipette into another sterile test tube given a concentration of 128. Another $1000 \mu \mathrm{l}$ of sterile Mueller Hinton broth is added to the tube containing 128 concentrations to reduce the concentration to 64 and then serially transferring $1000 \mu \mathrm{l}$ from it to the next tube and so on for $16,8,4,2,1,0.5$ and $0.25 \mu \mathrm{g} / \mathrm{ml}$ is achieved for the different antibiotics, about $1000 \mu \mathrm{l}$ was removed from the last tube and discarded. $700 \mu \mathrm{l}$ of the serially diluted different concentrations is pipette into the sterile eppendorf tubes then 10 $\mu \mathrm{l}$ of the standardized test organism were dispensed into the eppendorf tubes containing the different concentrations. The negative control tubes were different concentrations of antibiotics in MHB without the test isolates, while the positive control tubes contained $1000 \mu \mathrm{l}$ broth medium and each of the test organisms. All the test tubes were incubated for 18 to 24 hours at $37^{\circ} \mathrm{C}$. The MIC was determined visually by inspecting the tubes for turbidity post-incubation (matching the test tubes with test organisms with the corresponding negative control tubes). The MIC was reported as the lowest concentration of the test antibiotics which resulted in $100 \%$ inhibition of the test organism.

\subsection{Minimum Bactericidal Concentration (MBC)}

The minimum bactericidal concentration of the antibiotics was determined by further sub-culturing from the tubes which showed no visible growth in the MIC assay onto freshly prepared Mueller Hinton agar (MHA) plates. The culture plate containing bacteria were incubated at $37^{\circ} \mathrm{C}$ for 24 hours. The $\mathrm{MBC}$ was therefore taken as the lowest concentration that did not show any visible growth on the sub-cultured MHA plate [15].

\subsection{Determination of Multiple Antibiotic Resistance Index (MARI)}

Multiple Antibiotic Resistance Index (MARI), has been shown to be a cost effective and valid method of bacteria source tracking. Multiple antibiotic resistance indexes are calculated as the ratio of number of antibiotics to which an organism is resistant to total number of antibiotics to which the organism has been exposed [16]. The MAR indices of the isolates were calculated and noted. 


\subsection{Data Analysis}

Results were analysed using SPSS software version 25.0 for Windows (SPSS Inc. 2017 Chicago, Illinois, USA). Categorical variables were tested for association using Pearson Chi-square and Fisher exact test as appropriate. Significant level was set at $P$ value of 0.05 .

\section{Results}

\subsection{Prevalence of Uropathogen in the Study Areas}

Of the 489 urine samples examined, the overall prevalence of urinary tract infection was $26.4 \%$. The prevalence rate of UTI in the investigated areas such as Nsukka, Otukpo, Gboko and Kastina Ala was 31.8\%, 17.5\%, 34.3\% and 17.1\%, respectively (Table 1 ). Out of 130 positive samples, the prevalence of UTI was

Table 1. Prevalence of UTI among children attending some hospitals in the study areas based on sex and age.

\begin{tabular}{|c|c|c|c|c|c|c|c|c|}
\hline \multirow{2}{*}{ Location } & \multirow{2}{*}{ Parameter } & \multicolumn{2}{|c|}{ Gender } & \multirow{2}{*}{ Total } & \multicolumn{3}{|c|}{ Age (Year) } & \multirow{2}{*}{ Total } \\
\hline & & Male & Female & & $2-5$ & $6-9$ & $10-12$ & \\
\hline \multirow{5}{*}{ Nsukka } & $\mathrm{NE}$ & 121 & 102 & 223 & 127 & 62 & 34 & 223 \\
\hline & NI & 43 & 28 & 71 & 40 & 20 & 11 & 71 \\
\hline & P (\%) & 35.5 & 27.5 & 31.8 & 31.5 & 32.3 & 32.4 & 31.8 \\
\hline & $\mathrm{X}^{2}$ & \multicolumn{2}{|c|}{0.45} & \multicolumn{5}{|c|}{51.75} \\
\hline & $p$-value & \multicolumn{2}{|c|}{0.49} & \multicolumn{5}{|c|}{0.00} \\
\hline \multirow{5}{*}{ Otukpo } & $\mathrm{NE}$ & 64 & 62 & 126 & 65 & 27 & 34 & 126 \\
\hline & NI & 15 & 7 & 22 & 18 & 1 & 3 & 22 \\
\hline & P (\%) & 24 & 11.2 & 17.6 & 27.7 & 3.7 & 8.8 & 17.5 \\
\hline & $\mathrm{X}^{2}$ & \multicolumn{2}{|c|}{2.28} & \multicolumn{5}{|c|}{109.36} \\
\hline & $p$-value & \multicolumn{2}{|c|}{0.10} & \multicolumn{5}{|c|}{0.00} \\
\hline \multirow{5}{*}{ Gboko } & $\mathrm{NE}$ & 43 & 27 & 70 & 34 & 21 & 15 & 70 \\
\hline & NI & 17 & 7 & 24 & 10 & 10 & 4 & 24 \\
\hline & $\mathrm{P}(\%)$ & 39.5 & 25.9 & 34.3 & 29.4 & 47.6 & 26.7 & 34.3 \\
\hline & $\mathrm{X}^{2}$ & \multicolumn{2}{|c|}{0.81} & \multicolumn{5}{|c|}{33.46} \\
\hline & $p$-value & \multicolumn{2}{|c|}{0.37} & \multicolumn{5}{|c|}{0.00} \\
\hline \multirow{5}{*}{ Kastina Ala } & $\mathrm{NE}$ & 34 & 36 & 70 & 40 & 20 & 10 & 70 \\
\hline & NI & 6 & 7 & 13 & 7 & 4 & 2 & 13 \\
\hline & P (\%) & 17.6 & 19.4 & 18.6 & 17.5 & 20 & 20.0 . & 18.6 \\
\hline & $\mathrm{X}^{2}$ & \multicolumn{2}{|c|}{0.05} & \multicolumn{5}{|c|}{50.01} \\
\hline & $p$-value & \multicolumn{2}{|c|}{0.81} & \multicolumn{5}{|c|}{0.00} \\
\hline \multirow{5}{*}{ Overall } & $\mathrm{NE}$ & 262 & 227 & 489 & 266 & 130 & 93 & 489 \\
\hline & NI & 81 & 49 & 130 & 75 & 35 & 20 & 130 \\
\hline & P (\%) & 30.9 & 21.6 & 26.6 & 28.2 & 26.9 & 21.5 & 26.6 \\
\hline & $\mathrm{X}^{2}$ & \multicolumn{2}{|c|}{0.82} & \multicolumn{5}{|c|}{0.28} \\
\hline & $p$-value & \multicolumn{2}{|c|}{0.36} & \multicolumn{5}{|c|}{0.87} \\
\hline
\end{tabular}

NE: Number examined, NI: Number infected, P: Prevalence, Statistically significant at $p<0.05$. 
higher in males $81(30.9 \%)$ than in females $49(21.6 \%)$, but there was no statistically significant association between gender and UTI $(p=0.636)$ (Table 1$)$. The age categorizations of the study subjects were $2-5,6-9$ and $10-12$. This study revealed that the prevalence of UTI was greater among the age 2 - 5 (28.2\%), followed by the age group 6 - 9 (26.9\%), while the age group $10-12$ had the least prevalence of $21.5 \%$ (Table 1 ); although there was no statistically significant association between UTI and the age groups $(p=0.870)$.

The result of dipstick urinalysis showed that out of 489 sample examined, 36 (7.4\%) was positive for nitrite; $33(6.8 \%)$ for bilirubin, 8 (1.6\%) for blood, 10 (2.0\%) for urobilinogen, $111(22.7 \%)$ for protein, 31 (6.4\%) for ketone, $86(17.6 \%)$ for ascorbic acid and $22(4.5 \%)$ for glucose. The $\mathrm{pH}$ categorisation shows that 292 (59.8\%) had acidic $\mathrm{pH}$ urine followed by 142 (29.1) for neutral and 53 (10.9\%) alkaline $\mathrm{pH}$ (Table 2 ).

\subsection{Microorganisms Isolated from Urine Culture}

The prevalence of uropathogens among children attending hospitals in all the study areas according to urine samples culture, showed that four Gram-negative organisms were isolated and they are Klebsiella pneumonae, E. coli, Pseudomonas spp. and Proteus mirabilis (Figure 1(a)). Klebsiella pneumonae, was the most predominant organism $(88.8 \%)$ and it was more isolated from male children, followed by $E$. coli. It was observed that $E$. coli was the most predominant organism isolated from the female children (40.6\%), and also Pseudomonas spp was seen more in male children (45.0\%) and Proteus mirabilis was the least (13.8\%) (Figure 1(a)). The bacteria with highest prevalence in Nsukka, Otukpo, Gboko, and Kastina Ala were Klebsiella pneumonae (46.4\%) (Figure 1(b)), Klebsiella spp (58.3\%) (Figure 1(c)), E. coli (38.5\%) (Figure 1(d)), and Klebsiella spp (42.0\%) (Figure $1(\mathrm{e})$ ), respectively.

Table 2. Urinalysis of samples collected from children attending some hospitals.

\begin{tabular}{cccccc}
\hline \multirow{2}{*}{ Urinalysis } & \multicolumn{5}{c}{ Prevalence (\%) } \\
\cline { 2 - 6 } & Nsukka & Otukpo & Gboko & Kastina Ala & Overall \\
\hline Blood & $1(1.7 \%)$ & $4(3.2 \%)$ & $3(4.3 \%)$ & $3(4.3 \%)$ & $8(1.6)$ \\
Urobilinogen & $6(3.3 \%)$ & $3(2.4 \%)$ & $1(1.4 \%)$ & $1(1.4 \%)$ & $10(2.0)$ \\
Bilirubin & $14(8.3 \%)$ & $8(6.4 \%)$ & $7(10 \%)$ & $7(10 \%)$ & $33(6.8)$ \\
Protein & $59(35 \%)$ & $20(16 \%)$ & $22(31.4 \%)$ & $22(31.4 \%)$ & $111(22.7)$ \\
Nitrite & $14(8.3 \%)$ & $14(11.2 \%)$ & $1(1.4 \%)$ & $1(1.4 \%)$ & $36(7.4)$ \\
Ketone & $23(13.3 \%)$ & $1(0.8 \%)$ & $3(4.3 \%)$ & $3(4.3 \%)$ & $31(6.4)$ \\
Ascorbic acid & $42(25 \%)$ & $17(13.6 \%)$ & $20(28.6 \%)$ & $20(28.6 \%)$ & $86(17.6)$ \\
Glucose & $1(1.7 \%)$ & $6(4.8 \%)$ & $11(15.7 \%)$ & $11(15.7 \%)$ & $22(4.5)$ \\
pH Acidic & $138(81.7 \%)$ & $84(67.2 \%)$ & $25(35.7 \%)$ & $25(35.7 \%)$ & $292(59.8)$ \\
Neutral & $62(36.7 \%)$ & $34(27.2 \%)$ & $22(31.4 \%)$ & $22(31.4 \%)$ & $142(29.1)$ \\
Alkaline & $23(13.3 \%)$ & $7(5.6 \%)$ & $22(31.4 \%)$ & $22(31.4 \%)$ & $53(10.9)$ \\
& $\mathrm{N}=\mathbf{2 2 3}$ & $\mathrm{N}=126$ & $\mathrm{~N}=70$ & $\mathrm{~N}=70$ & $\mathrm{~N}=489$ \\
\hline
\end{tabular}




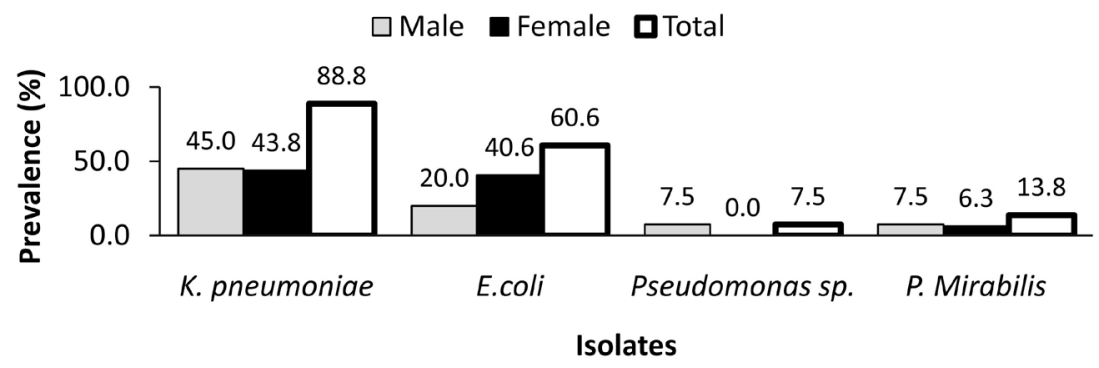

(a)

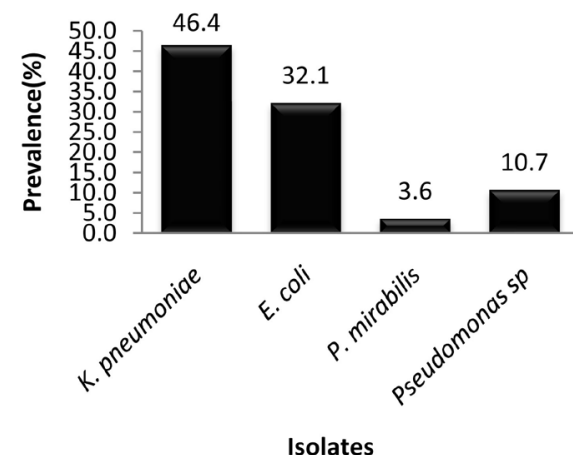

(b)

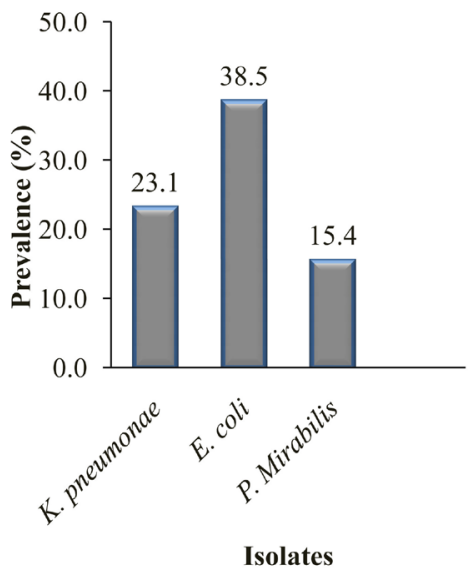

(d)

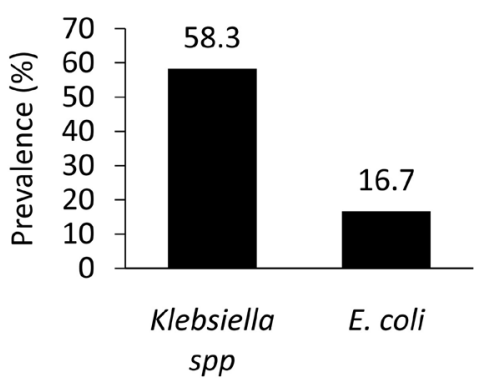

Isolates

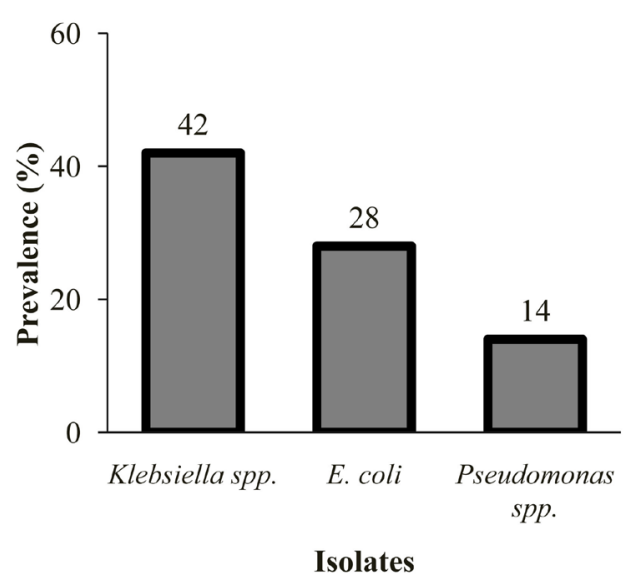

(e)

Figure 1. (a) Overall frequency of the bacterial isolates from children with UTI; (b) in Nsukka; (c) Otukpo; (d) in Gboko; (e) in Kastina Ala.

Evaluation of antibiotic susceptibility patterns of isolates to antibiotics used in the treatment of UTI in children presenting at some hospitals in the study areas.

The in-vitro antibiotic susceptibility tests were made on a total of 52 randomly selected isolates, which includes 16 from Nsukka, 12 from Otukpo, 16 from Gboko and 8 from Kastina Ala. This study showed that most of the isolate were highly resistant to Augmentin, Cotrimoxazoel, Amoxicilin and Tetracycline, while some of the isolate shows intermediate resistant to Nitrofurantoin and Nalixidic acid. Ofloxacine and Gentamicin were the most effective antibiotics against the isolates from all the study areas (Supplementary materials: Tables 1-4). K. pneumoniae isolates from Nsukka (56.3\%), Otukpo (55.6\%) and K. Ala 
Table 3. Overall percentage antibiotic susceptibility pattern of Gram-negative bacteria isolates.

\begin{tabular}{lcccc}
\hline Loaction & Isolates & Susceptible (\%) & Intermediate (\%) & Resistant (\%) \\
\hline \multirow{2}{*}{ Nsukka } & E. coli & $9(28.1)$ & $6(18.8)$ & $17(53.1)$ \\
& K. pneumonia & $16(25.0)$ & $12(18.8)$ & $36(56.3)$ \\
& P. mirabilis & $2(25.0)$ & $2(25.0)$ & $4(50.0)$ \\
\multirow{2}{*}{ Otukpo } & Pseudomonas spp. & $4(16.7)$ & $3(12.5)$ & $17(70.8)$ \\
& E. coli & $9(37.5)$ & $1(4.2)$ & $14(58.3)$ \\
\multirow{2}{*}{ Gboko } & Kneumonia & $26(36.1)$ & $6(8.3)$ & $40(55.6)$ \\
& K. pneumonia & $19(39.6)$ & $3(6.3)$ & $26(54.2)$ \\
& Proteus mirabilis & $11(34.4)$ & $6(18.8)$ & $16(50.0)$ \\
& E. coli & $9(37.5)$ & $2(6.3)$ & $19(59.4)$ \\
K. Ala & K. pneumonia & $9(28.1)$ & $3(12.5)$ & $12(50.0)$ \\
& Pseudomonas spp. & $3(37.5)$ & $6(18.8)$ & $17(53.1)$ \\
\hline
\end{tabular}

Table 4. Summary of antibiotic susceptibility pattern of all Gram-negative bacteria isolates to the antibiotics.

\begin{tabular}{cccccccccc}
\hline Isolate & R/S (\%) & AUG & OFL & GEN & NAL & NIT & COT & AMO & TET \\
\hline \multirow{2}{*}{ E. coli } & S & 0.0 & 84.6 & 84.6 & 23.1 & 100.0 & 0.0 & 0.0 & 16.7 \\
& R & 100.0 & 15.4 & 15.4 & 76.9 & 0.0 & 100.0 & 100.0 & 83.3 \\
K. pneumonia & S & 0.0 & 81.5 & 59.3 & 3.7 & 63.0 & 11.1 & 0.0 & 22.2 \\
& $\mathrm{R}$ & 100.0 & 18.5 & 40.7 & 96.3 & 37.0 & 88.9 & 100.0 & 77.8 \\
P. mirabilis & $\mathrm{S}$ & 0.0 & 80.0 & 100.0 & 20.0 & 40.0 & 0.0 & 0.0 & 20.0 \\
& $\mathrm{R}$ & 100.0 & 20.0 & 0.0 & 80.0 & 60.0 & 100.0 & 100.0 & 80.0 \\
Pseudomonas spp. & $\mathrm{S}$ & 0.0 & 75.0 & 25.0 & 25.0 & 50.0 & 0.0 & 0.0 & 0.0 \\
& $\mathrm{R}$ & 100.0 & 25.0 & 75.0 & 75.0 & 50.0 & 100.0 & 100.0 & 100.0 \\
\hline
\end{tabular}

KEY: R = Resistant (+Intermediate), $\mathrm{S}=$ Sensitive. AUG = Augmentin, OFL = Ofloxacin, GEN = Gentamicin, NAL $=$ Nalixidic Acid, NIT $=$ Nitrofurantoin, COT $=$ Cotrimoxazole, AMO $=$ Amoxicilin, TET, Tetracycline.

(53.1\%) were the most resistant to the test antibiotics, while E. coli isolates from Gboko had highest percentage of resistance (Table 3). More than $50 \%$ of each of the bacteria isolates were resistant to NAL, COT and TET (Table 4).

Overall average MAR index of all the isolates from the different region revealed that Pseudomonassp had the highest MARI of 0.80 , followed by $K$. pneumoniae (0.73), and P. mirabilis (0.72) and E. coli (0.64) (Figure 2(a)). The average MAR index of isolates from the different study areas shows that Pseudomonassp isolates from Nsukka had the highest MARI at 0.9, followed by $K$. pneumoniae (all locations) and P. mirabilis (Nsukka) (0.8). E. coli had the least MAR index of 0.6 (Figure 2(a)). 


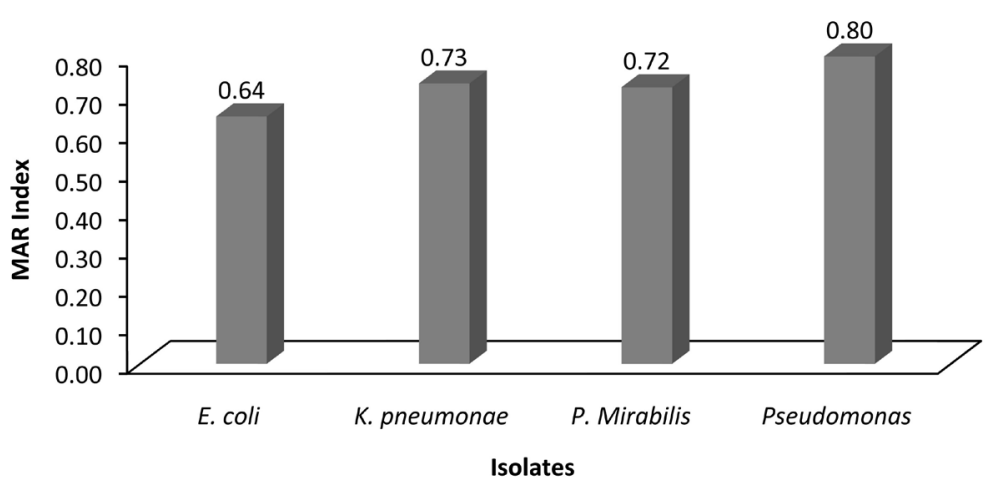

(a)

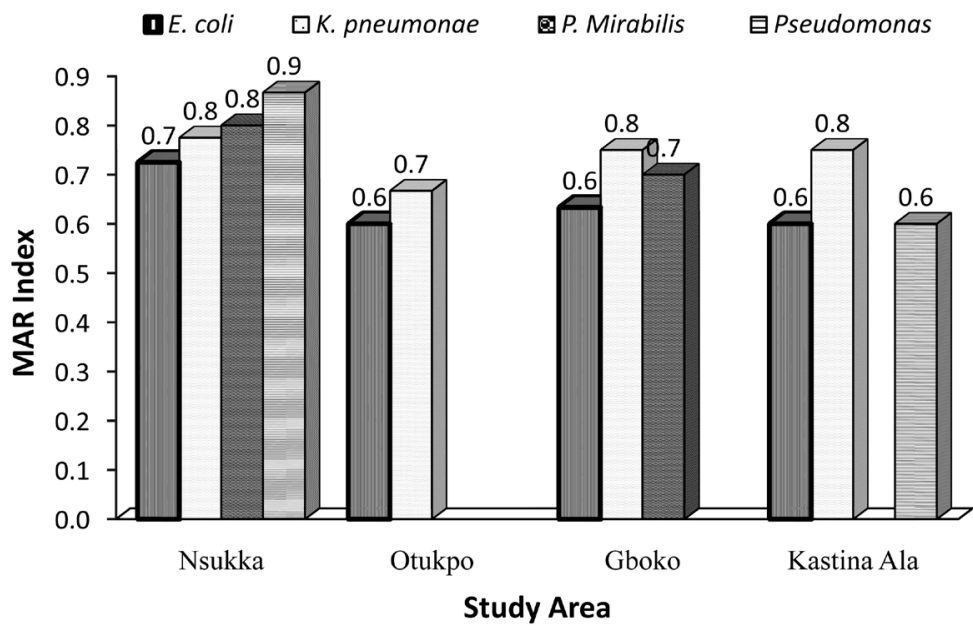

(b)

Figure 2. (a) Overall average MAR index of isolates; (b) Average MAR index of isolates from different study areas.

\subsection{MIC and MBC of the Antibiotics}

The MICs of nitrofurantoin against Pseudomonas sp, K. pneumoniae, P. mirabilis, and E. coli isolates from all the study areas ranged from $8.0-128.0,16.0$ 128.0, $16.0-64.0$, and $8.0-64.0 \mu \mathrm{g} / \mathrm{ml}$, respectively, while the MBCs were $64.0->128.0,32.0->128.0,128.0->128.0$, and $32.0->128.0 \mu \mathrm{g} / \mathrm{ml}$, respectively (Tables 5-8). The MICs of ofloxacine against the sameisolates ranged from 4.0 $16.0,4.0-32.0,8.0-16.0$, and $0.5-16.0 \mu \mathrm{g} / \mathrm{ml}$, respectively, while the MBCs were $8.0-128.0,16.0-128.0,16.0-64.0$, and $8.0-32.0 \mu \mathrm{g} / \mathrm{ml}$, respectively (Tables 5-8). The MICs of gentamicin against the sameisolates ranged from 4.0 16.0, $8.0-64.0,8.0-64.0$, and $8.0-32.0 \mu \mathrm{g} / \mathrm{ml}$, respectively, while the MBCs were 32.0- > 128.0, 32.0- > 128.0, $32.0-128.0$, and $16.0-64.0 \mu \mathrm{g} / \mathrm{ml}$, respectively (Tables 5-8).

\section{Discussion}

UTI is one of the infections frequently encountered in hospitals and diagnostic laboratories [17]. Therefore, performing area-specific monitoring studies is essential which may aid in choosing the correct empirical treatment for the 
Table 5. The MIC and MBC of antibiotics against isolates from Nsukka.

\begin{tabular}{ccccccc}
\hline \multirow{2}{*}{ Isolates } & \multicolumn{2}{c}{ Nitrofurantoin $(\mu \mathrm{g} / \mathrm{ml})$} & \multicolumn{2}{c}{ Ofloxacine $(\mu \mathrm{g} / \mathrm{ml})$} & \multicolumn{2}{c}{ Gentamicin $(\mu \mathrm{g} / \mathrm{ml})$} \\
\cline { 2 - 7 } & MIC & MBC & MIC & MBC & MIC & MBC \\
\hline Pseudomonas sp 4 & 32.0 & $>128.0$ & 8.0 & 32.0 & 32.0 & 64.0 \\
K. pneumoniae 39 & 32.0 & $>128.0$ & 16.0 & 64.0 & 64.0 & 128.0 \\
P. mirabilis 38 & 16.0 & $>128.0$ & 8.0 & 16.0 & 8.0 & 32.0 \\
E. coli 29 & 16.0 & 64.0 & 2.0 & 8.0 & 8.0 & 16.0 \\
K. pneumoniae 92 & 64.0 & $>128.0$ & 16.0 & 64.0 & 32.0 & 128.0 \\
K. pneumoniae 47 & 16.0 & 32.0 & 8.0 & 16.0 & 16.0 & 32.0 \\
Pseudomonas $\mathrm{sp} 51$ & 128.0 & $>128.0$ & 32.0 & 128.0 & 64.0 & $>128.0$ \\
E. coli 40 & 64 & 128.0 & 0.5 & 8.0 & 8.0 & 32.0 \\
K. pneumoniae 55 & 32.0 & 128.0 & 64.0 & 128.0 & 64.0 & $>128.0$ \\
E. coli 80 & 32.0 & $>128.0$ & 2.0 & 32.0 & 16.0 & 64.0 \\
\hline
\end{tabular}

$>128.0=$ No MBC; MIC-Minimum inhibitory concentration; MBC-Minimum bactericidal concentration.

Table 6. The MIC and MBC of antibiotics against isolates from Otukpo.

\begin{tabular}{ccccccc}
\hline \multirow{2}{*}{ Isolates } & \multicolumn{1}{c}{ Nitrofurantoin $(\mu \mathrm{g} / \mathrm{ml})$} & Ofloxacine $(\mu \mathrm{g} / \mathrm{ml})$ & Gentamicin $(\mu \mathrm{g} / \mathrm{ml})$ \\
\cline { 2 - 6 } & MIC & MBC & MIC & MBC & MIC & MBC \\
\hline E. coli 10 & 32.0 & $>128.0$ & 2.0 & 16.0 & 8.0 & 64.0 \\
K. pneumoniae 77 & $>128.0$ & $>128.0$ & 16.0 & 64.0 & 64.0 & $>128.0$ \\
K. pneumoniae 49 & 64.0 & $>128.0$ & 4.0 & 16.0 & 8.0 & 32.0 \\
E. coli 60 & 64.0 & 64.0 & 4.0 & 8.0 & 16.0 & 32.0 \\
K. pneumoniae 5 & 64.0 & $>128.0$ & 32.0 & 128.0 & 32.0 & $>128.0$ \\
E. coli 34 & 16.0 & 32.0 & 16.0 & 32.0 & 16.0 & 32.0 \\
K. pneumoniae 28 & 128.0 & $>128.0$ & 32.0 & 64.0 & 64.0 & $>128.0$ \\
E. coli 20 & 64 & 128.0 & 4.0 & 16.0 & 16.0 & 64.0 \\
E. coli 11 & 8.0 & 64.0 & 8.0 & 32.0 & 32.0 & 64.0 \\
K. pneumoniae 98 & 64.0 & $>128.0$ & 32.0 & 64.0 & 64.0 & 128.0 \\
\hline
\end{tabular}

$>128.0=$ No MBC; MIC-Minimum inhibitory concentration; MBC-Minimum bactericidal concentration.

Table 7. The MIC and MBC of antibiotics against isolates from Gboko.

\begin{tabular}{|c|c|c|c|c|c|c|}
\hline \multirow{2}{*}{ Isolates } & \multicolumn{2}{|c|}{ Nitrofurantoin $(\mu \mathrm{g} / \mathrm{ml})$} & \multicolumn{2}{|c|}{ Ofloxacine $(\mu \mathrm{g} / \mathrm{ml})$} & \multicolumn{2}{|c|}{ Gentamicin $(\mu \mathrm{g} / \mathrm{ml})$} \\
\hline & MIC & $\mathrm{MBC}$ & MIC & MBC & MIC & MBC \\
\hline K. pneumoniae 55 & 32.0 & $>128.0$ & 8.0 & 16.0 & 8.0 & 32.0 \\
\hline$K \cdot$ pneumoniae 30 & 128.0 & $>128.0$ & 32.0 & 64.0 & 64.0 & $>128.0$ \\
\hline P. mirabilis 7 & 64.0 & $>128.0$ & 16.0 & 64.0 & 64.0 & 128.0 \\
\hline E. coli 10 & 16.0 & 64.0 & 8.0 & 8.0 & 16.0 & 32.0 \\
\hline K. pneumonia 17 & 128.0 & $>128.0$ & 32.0 & 128.0 & 32.0 & $>128.0$ \\
\hline E. coli 20 & 32.0 & 64.0 & 16.0 & 32.0 & 32.0 & 64.0 \\
\hline P. mirabilis 41 & 32.0 & 128.0 & 8.0 & 16.0 & 16.0 & 64.0 \\
\hline E. coli 39 & 32.0 & 128.0 & 8.0 & 16.0 & 16.0 & 64.0 \\
\hline E. coli 60 & 64.0 & 128.0 & 16.0 & 32.0 & 32.0 & 64.0 \\
\hline P. mirabilis 62 & 64.0 & $>128.0$ & 16.0 & 64.0 & 64.0 & 128.0 \\
\hline
\end{tabular}

$>128.0=$ No MBC; MIC-Minimum inhibitory concentration; MBC-Minimum bactericidal concentration. 
Table 8. The MIC and MBC of antibiotics against isolates from Kastina Ala.

\begin{tabular}{ccccccc}
\hline \multirow{2}{*}{ Isolates } & \multicolumn{2}{c}{ Nitrofurantoin $(\mu \mathrm{g} / \mathrm{ml})$} & \multicolumn{2}{c}{ Ofloxacine $(\mu \mathrm{g} / \mathrm{ml})$} & \multicolumn{2}{c}{ Gentamicin $(\mu \mathrm{g} / \mathrm{ml})$} \\
\cline { 2 - 7 } & MIC & MBC & MIC & MBC & MIC & MBC \\
\hline K. pneumonia 15 & 64.0 & $>128.0$ & 16.0 & 64.0 & 32.0 & 128.0 \\
Pseudomonas sp 2 & 64.0 & 128.0 & 4.0 & 8.0 & 16.0 & 32.0 \\
Pseudomonas sp 10 & 64.0 & 128.0 & 16.0 & 32.0 & 32.0 & 64.0 \\
E. coli 45 & 32.0 & 64.0 & 8.0 & 32.0 & 32.0 & 64.0 \\
E. coli 70 & 16.0 & 32.0 & 4.0 & 16.0 & 16.0 & 32.0 \\
Pseudomonas sp 65 & 8.0 & 64.0 & 8.0 & 32.0 & 32.0 & 64.0 \\
E. coli 30 & 32.0 & 64.0 & 8.0 & 8.0 & 16.0 & 32.0 \\
K. pneumoniae 25 & 64.0 & $>128.0$ & 32.0 & 128.0 & 32.0 & 64.0 \\
K. pneumoniae 54 & 64.0 & $>128.0$ & 32.0 & 64.0 & 64.0 & 128.0 \\
\hline 128.0 = No MBC; MIC-Minimum inhibitory concentration; MBC-Minimum bactericidal concentration.
\end{tabular}

infection/disease. In this study, the overall prevalence of UTI among children attending hospitals in the areas was $26.4 \%$. Highest prevalence rate of UTI was observed among children attending hospitals in Gboko (34.3\%), followed by Nsukka (31.8\%), Otukpo (17.5\%) and Kastina Ala (17.1\%). The observed UTI prevalence rate in Gboko and Nsukka including overall prevalence, are higher than prevalence rate of UTI (24.7\%) reported byDada and Aruwa [18] for children (5 - 11 years) in Ondo State, Nigeria. In another study in Ebonyi State, Moses et al. reported a higher prevalence rate of $48 \%$ among school children (4 - 12 years) in a rural area [7].

Consequently, on the basis of laboratory tests of urine using urine dipstick, it was found that $36(7.4 \%), 8(1.6 \%), 10(2 \%)$ and $33(6.8 \%)$ were positive for nitrite, blood, urobilinogen and bilirubin respectively, which may be an indication of UTI, haematuria, or viral infection either hepatitis or jaundice [19].

We observed that the overall prevalence of bacteriuria was higher in male (30.9\%) than in female $(21.6 \%)$ children, even in some study areas like Nsukka, Otukpo and Gboko, contrary to what has been reported in some literature. But in Kastina Ala, female children had higher rate of UTI than their male counterpart. Similarly, higher prevalence rate of UTI in male than female infants have been reported in Brazil (male 3.7\%, female 2\%) [20], Korea (Male 74\%, female 26\%) [21] and Nepal (male 53\%, female 47\%) [8]. The immune system that has not fully developed and exposures to soil and faecal pathogen may be some of the predisposing factors to UTI in infants/children. UTI rate at neonate and infant is usually higher in males than in females, and in this study, more samples were got from infants, which may have resulted in higher rate in males. In contrary, higher UTI prevalence rates in female than in male children have been reported in Ondo State [22] and Osun State, Nigeria [12] and even in other countries [9] [23]. The prevalence rate of UTI decreased with increase in age of the children, and in our study the infants ( 2 - 5 years) had the highest prevalence 
rate which is similar to other reports [8] [24]. Our study however demonstrated significant association between age differences in the occurrence of UTI among children under the age of 12 years in all the regions under study ( $p=0.000001)$.

In this study, the most predominant bacterium recovered from the urine of the children was Klebsiella pneumonia, followed by E. coli, Pseudomonas spp. and $P$. mirabilis (Figure 1(a)). K. pneumonia, Pseudomonas spp. and P. mirabilis were more in male children while $E$. coli was more in female children. The pattern and frequency of occurrence of the bacterial isolates found in this study are similar to those reported previously [25]. On the contrary, many studies have reported that the most predominant and frequently isolated bacteria are Staphylococcus aureus [7] [26], and E. coli [8] [9] [18] [23] [27] [28].

The isolates tested were $100 \%$ resistant to augmentin and amoxicillin but susceptible to ofloxacin followed to some extent by gentamycin and nitrofurantoin (which makes them the first line antibiotics for treatment of UTI in children). In addition, $76.9 \%, 100 \%$ and $83.3 \%$ of $E$. coli isolates were resistant to NAL, COT and TET, respectively. $K$. pneumonia (96.3\%, $88.9 \%$ and $77.8 \%$, respectively), $P$. mirabilis $(80.0 \%, 100 \%$ and $80 \%$, respectively), and Pseudomonas spp. (75\%, $100 \%$ and $100 \%$, respectively) isolates were resistant to the same drugs. Similar to our finding, there are reports on the effectiveness of gentamycin and ofloxacin against E. coli [6] [29] and its resistant to TET, COT, NAL, AMO, NIT [6]. A study in Nigeria reported susceptibility of similar isolates to OFL NIT, and their resistance to TET and COT [30]. Merga Duffa et al. and Nazme et al. have reported the resistance of some Gram-negative isolates to NAL [5] and COT [27] [28] and the susceptibility of $P$. mirabilis to the same drug [5], similar to our findings. On the contrary, the resistance of E. coli to OFL [8] and K. pneumonia to NIT but susceptible to AMO [31] have been reported, as well as the suceptiblility of E. coli, K. pneumonia and P. mirabilis to NAL [32]. Pouladfar et al. investigation showed that $K$. pneumonia was susceptible to TET, and similar to our findings resistant to AMO, COT, NIT, although, Pseudomonas sp. was resistant to NAL and GEN [6]. The sensitivity to NIT in our study is not in tandem with other reports which showed that $P$. mirabilis and $P$. aeruginosa were resistant to NIT [26].

\section{Conclusions}

The most predominant organism in this study is $K$. pneumonia, followed by $E$. coli, Pseudomonas spp. and P. mirabilis. In addition, $K$. pneumonia and Pseudomonas spp predominated more in male than in female children. The resistant patterns of the isolates to some of the antibiotics show that the first line of antibiotics for treatment of UTI in children in these areas should be Ofloxacine and Gentamicin.

The observed antibiotic resistant patterns may be due to long term use of some of these drugs over the years. Also, prescriptions of antibiotics without laboratory guidance as well as over the counter sales of antibiotics without prescription are rife in the Nigerian setting. 


\section{Availability of Data and Materials}

Data are all contained within the paper. The datasets from the analyses are available from the corresponding author on a reasonable request.

\section{Consent for Publication}

Not applicable.

\section{Funding}

This research did not receive any specific grant from funding agencies in the public, commercial, or not-for-profit sectors.

\section{Conflicts of Interest}

The authors declare that they have no competing interests.

\section{References}

[1] McLellan, L.K. and Hunstad, D.A. (2016) Urinary Tract Infection: Pathogenesis and Outlook. Trends in Molecular Medicine, 22, 946-957. https://doi.org/10.1016/j.molmed.2016.09.003

[2] Habib, S. (2012) Highlights for Management of a Child with a Urinary Tract Infection. International Journal of Pediatrics, 2012, Article ID: 943653. https://doi.org/10.1155/2012/943653

[3] Mohammed, M.A., Alnour, T.M.S., Shakurfo, O.M. and Aburass, M.M. (2016) Prevalence and Antimicrobial Resistance Pattern of Bacterial Strains Isolated from $\mathrm{Pa}$ tients with Urinary Tract Infection in Messalata Central Hospital, Libya. Asian Pacific Journal of Tropical Medicine, 9, 771-776. https://doi.org/10.1016/j.apjtm.2016.06.011

[4] Ogbukagu, C.M., Anakwenze, V.N., Ekwealor, C.C., Ezemba, C.C. and Ekwealor, I.A. (2016) Incidence of Urinary Tract Infections (UTI) amongst Patients Attending Primary Health Centres in Anambra State. Advances in Microbiology, 6, 537-547. https://doi.org/10.4236/aim.2016.67054

[5] Merga Duffa, Y., Terfa Kitila, K., Mamuye Gebretsadik, D. and Bitew, A. (2018) Prevalence and Antimicrobial Susceptibility of Bacterial Uropathogens Isolated from Pediatric Patients at Yekatit 12 Hospital Medical College, Addis Ababa, Ethiopia. International Journal of Microbiology, 2018, Article ID: 8492309. https://doi.org/10.1155/2018/8492309

[6] Pouladfar, G., Basiratnia, M., Anvarinejad, M., Abbasi, P., Amirmoezi, F. and Zare, S. (2017) The Antibiotic Susceptibility Patterns of Uropathogens among Children with Urinary Tract Infection in Shiraz. Medicine (Baltimore), 96, e7834. https://doi.org/10.1097/MD.0000000000007834

[7] Moses, A., Michael, E., Chukwudi, A. and Nwofoke, O.E. (2012) Asymptomatic Urinary Tract Infection among School Children in Rural Area of Ebonyi State Scholars Research Library. Annals of Biological Research, 3, 2353-2356.

[8] Shah, G., Pokhrel, B., Shah, A.K. and Bahadur, P. (2016) Bacterial Pathogens and Antibiotic Resistance Patterns in Children with Urinary Tract Infection Admitted at Tertiary Hospital in Nepal. Journal of Patan Academy of Health Sciences, 3, 32-35. https://doi.org/10.3126/jpahs.v3i2.20274 
[9] Saeed, C., Al-Otraqchi, K. and Mansoor, I. (2015) Prevalence of Urinary Tract Infections and Antibiotics Susceptibility Pattern among Infants and Young Children in Erbil City. Zanco Journal of Medical Sciences, 19, 915-922. https://doi.org/10.15218/zjms.2015.0012

[10] Patwardhan, V., Kumar, D., Goel, V. and Singh, S. (2017) Changing Prevalence and Antibiotic Drug Resistance Pattern of Pathogens Seen in Community-Acquired Pediatric Urinary Tract Infections at a Tertiary Care Hospital of North India. Journal of Laboratory Physicians, 9, 264-268. https://doi.org/10.4103/JLP.JLP 14916

[11] Ibeneme, C.A., Oguonu, T., Okafor, H.U., Ikefuna, A.N. and Ozumba, U.C. (2014) Urinary Tract Infection in Febrile under Five Children in Enugu, South Eastern Nigeria. Nigerian Journal of Clinical Practice, 17, 624-628. https://doi.org/10.4103/1119-3077.141430

[12] Aiyegoro, A.O., Igbinosa, O.O., Ogunmwonyi, N.I., Odjadjare, E.E., Igbinosa, E.O., Okoh, I.A., et al. (2007) Incidence of Urinary Tract Infections (UTI) among Children and Adolescents in Ile-Ife, Nigeria. African Journal of Microbiology Research, 1, 13-19.

[13] Stefaniuk, E.M. (2018) The Usefulness of Chromogenic Media for Qualitative and Semi-Quantitative Diagnostic of Urinary Tract Infections. Polish Journal of Microbiology, 67, 213-218. https://doi.org/10.21307/pjm-2018-031

[14] Bauer, A.W., Kirby, W.M.M., Sherris, J.C. and Turck, M. (1966) Antibiotic Susceptibility Testing by a Standardized Single Disk Method. American Journal of Clinical Pathology, 45, 493-496. https://doi.org/10.1093/ajcp/45.4 ts.493

[15] Andrews, J.M. (2002) Determination of Minimum Inhibitory Concentrations. Journal of Antimicrobial Chemotherapy, 48, 5-16. https://doi.org/10.1093/jac/dkf083

[16] Al-Hamdani, M.A. and Hamad, I.G. (2012) Study of Plasmid Profile, Susceptibility Patterns of Clinical Staphylococcus aureus Isolated from Patients with Otitis Media in Basrah. 38.

[17] Doern, C.D. and Richardson, S.E. (2016) Diagnosis of Urinary Tract Infections in Children. Journal of Clinical Microbiology, 54, 2233-2242. https://doi.org/10.1128/JCM.00189-16

[18] Dada, E. and Aruwa, C. (2016) Asymptomatic Bacteriuria Prevalence among Primary School Children in the Federal University of Technology, Akure (Futa), Ondo State. Journal of Applied Life Sciences International, 4, 1-8. https://doi.org/10.9734/JALSI/2016/24730

[19] Roberts, J.R. (2015) Urine Dipstick Testing: Everything You Need to Know [Internet]. Emergency Medicine News.

https://alliedhealth.ceconnection.com/files/UrineDipstickTestingEverythingYouNee dtoKnow-1440776910971.pdf

[20] Simões e Silva, A.C., Oliveira, E.A., Simões e Silva, A.C. and Oliveira, E.A. (2015) Update on the Approach of Urinary Tract Infection in Childhood. Jornal de Pediatria, 91, S2-S10. https://doi.org/10.1016/j.jpedp.2015.09.008

[21] Ko, S.Y., Lee, J.H. and Rho, Y. (2018) Relationship between Obesity and UTI in Children under 2 Years of Age Admitted with Fever. Childhood Kindey Diseases, 22, 58-63. https://doi.org/10.3339/jkspn.2018.22.2.58

[22] Dada, E. and Aruwa, C. (2016) Asymptomatic Bacteriuria Prevalence among Primary School Children in the Federal University of Technology, Akure (Futa), Ondo State, Nigeria. Journal of Applied Life Sciences International, 4, 2394-1103. https://doi.org/10.9734/JALSI/2016/24730 
[23] Yilmaz, Y., Tazegun, Z.T., Aydin, E. and Dulger, M. (2016) Bacterial Uropathogens Causing Urinary Tract Infection and Their Resistance Patterns among Children in Turkey. Iranian Red Crescent Medical Journal, 18, 4-7. https://doi.org/10.5812/ircmj.26610

[24] Agbagwa, O.E. and Emeka, I. (2015) The Prevalence of UTI Pathogens in Urine Specimen Obtained from a Hospital in Rivers State Nigeria. Journal of Microbiology Research, 5, 143-148.

[25] Ibekwe, R., Muoneke, V. and Ibekwe, M. (2012) Childhood Urinary Tract Infection in Abakaliki: Etiological Organisms and Antibiotic Sensitivity Pattern. Annals of Medical and Health Science Research, 2, 29. https://doi.org/10.4103/2141-9248.96933

[26] Shrestha, L.B., Baral, R., Poudel, P. and Khanal, B. (2019) Clinical, Etiological and Antimicrobial Susceptibility Profile of Pediatric Urinary Tract Infections in a Tertiary Care Hospital of Nepal. BMC Pediatrics, 19, 1-8.

https://doi.org/10.1186/s12887-019-1410-1

[27] Nazme, N.I., Amin, A.A., Jalil, F., Sultana, J. and Fatema, N.N. (2018) Bacteriological Profile of Urinary Tract Infection in Children of a Tertiary Care Hospital. Bangladesh Journal of Child Health, 41, 77-83. https://doi.org/10.3329/bjch.v41i2.36102

[28] Hussein, N.H., Rasool, K.H., Taha, B.M. and Hussein, J.D. (2017) Prevalence and Antimicrobial Susceptibility Patterns of Bacteria Isolated from Urinary Tract Infections (UTIs) in Children at Children Hospital in Baghdad. Al-Kindy College Medical Journal, 13, 13-18.

[29] Vigi, C., Gaurav, S., Naveen, C. and Raghuvanshi, R.K. (2016) High Prevalence of Multiple Drug Resistance among Pediatric Escherichia coli Infections. International Journal of Medical Research and Health Sciences, 5, 166-169.

[30] Oluwafemi, T., Akinbodewa, A., Ogunleye, A. and Adejumo, O. (2018) Urinary Tract Infections and Antibiotic Sensitivity Pattern of Uropathogens in a Tertiary Hospital in South West, Nigeria. Sahel Medical Journal, 21, 18. https://doi.org/10.4103/1118-8561.232779

[31] Al-Mijalli, S.H. (2017) Bacterial Uropathogens in Urinary Tract Infection and Antibiotic Susceptibility Pattern in Riyadh Hospital, Saudi Arabia. Cellular \& Molecular Medicine, 3, 1-5. https://doi.org/10.21767/2573-5365.100028

[32] El-Gamasy, M. (2017) Prevalence of Infective Organisms of Infections of Urinary Tract in a Sample of Arab Infants and Children. Journal of Integrative Nephrology and Andrology, 4, 136. https://doi.org/10.4103/jina.jina 2117 